\title{
A Fotografia Como um Meio de Expressão Entre Sujeito e Telefone Móvel na Cultura e Arte da Mobilidade
}

\author{
Photography as a Medium of Expression Between Subject and Mobile Phone in the Culture and Art of \\ Mobility
}

\author{
Luciana Abitante Swarowsky \\ Universidade Federal de Santa Maria \\ lubitante@gmail.com
}

\begin{abstract}
Having the growing potential for mobile communication in our culture, whose daily life has become increasingly more influenced by new medias, this article aims to think mobile photograph as well as its creation from a dialogue between two distinct subjects: a sensitive one (the man) and a depersonalized one (the machine). In this text, the mobile phone represents the depersonalized subject and is seen as an apparatus capable of transforming the conceptual thinking in pictures as well transforms the sensitive subject in a dependent machinic. Thereby, it is possible to think the creation of mobile photography as an object originated from an interactive process between two subjects that are continuously confronting and interacting, moving and swapping positions in the reason of the photographic image.
\end{abstract}

Keywords: Photography; Expression; Mobile Phone; Art of Mobility.

A crescente inclusão de objetos culturais como o telefone móvel em produções fotográficas contemporâneas é consequência da apropriação de ferramentas tecnológicas para a criação de meios de expressão não apenas na arte, como também em nosso cotidiano de um modo geral. Beneficiados pelos avanços da tecnologia da comunicação móvel, muitos destes dispositivos tornaram-se objetos híbridos e multifuncionais, constituindo "novas mídias" (LEV MANOVICH, 2005) capazes de facilitar o ato de criar, armazenar, distribuir e visualizar dados diversos, e assim modelar novas práticas e comportamentos sociais.

Embora considerado por alguns teóricos um meio que banaliza o ato fotográfico, o telefone móvel adquire um caráter significativo na cultura atual e vem se consolidando como uma ferramenta de expressão plástica que, dia após dia, possibilita diferentes poéticas, especialmente no campo da fotografia no qual parece reafirmar a infinidade da técnica fotográfica.

O surgimento da fotografia móvel, não sem consequência para o aparecimento e uso de um espaço artístico em crescente ascensão, é uma realidade que não se pode contornar. Tal como a fotografia tradicional a fotografia móvel impõe aos olhos humanos uma visão anteriormente percebida, faz emergir inúmeros interesses através de sua unicidade imagética e desperta no observador uma sensação pertencente somente ao seu imaginário. Capaz de ultrapassar os diferentes campos da razão e do sensível, sua força testemunhal, possibilita não apenas a criação mas, também, a documentação, a denúncia e o autoconhecimento (KOSSOY, 2001).
São particularidades que se tornam aparências sensíveis a cada disparo efetivo do obturador do telefone móvel, e instigam o desejo de refletir as especificidades desse modo recente de reproduzir o visível. Passando a intensificar um modelo de ligação social entre os indivíduos e o mundo de maneira automática, direta e instantânea, os telefones móveis assim se diferenciam dos demais aparatos fotográficos convencionais mesmo com suas limitações perante a técnica de captura. Fluindo e se estabelecendo na velocidade de sinais eletrônicos, a ligação que eles proporcionam - entre o homem e o mundo - desponta de maneira intensa como uma manifestação do "universo de software" (BAUMAN, 2001), cujas dimensões espaço-temporais são completamente alteradas, pois já não significam nenhuma espécie de barreira ou obstáculo.

Como consequência deste universo de coordenadas tênues e matérias efêmeras, deparamo-nos com um aparelho elaborado de tal forma que sua simplicidade de manuseio, ao mesmo tempo em que esconde a sua complexa capacidade de simulação, também oferece um leque de possibilidades operacionais para se trabalhar a fotografia móvel.

Originada do latim, a palavra aparelho (apparatus) deriva dos verbos adparare e praeparare. Verbos que indicam, na concepção de Flusser (2011), prontidão para algo, ou seja, uma maneira de estar à espreita ou à espera de algo, bem como disponibilidade para algo. Imerso neste contexto, a grande maioria das capturas fotográficas são, de um modo geral, provenientes de uma interação entre um sujeito e um aparelho fotográfico, comparada muitas vezes a uma caça imagética. 
Tal como mencionam Susan Sontag e Roland Barthes, esta analogia atribuída ao gesto fotográfico produz sentido e caráter brutal ao gênero dos dispositivos fotográficos e por sua vez, também ao telefone móvel quando na posição de uma câmera fotográfica. Logo, programado para fotografar, é possível afirmar que com o telefone móvel o homem passou a ter mais um instrumento de caça capaz de captar instantes e torná-los visíveis, evidenciando assim características existenciais de caráter social e artístico de muitas culturas.

Como um hardware de potencialidades diversas e inscritas em seu interior, o telefone móvel como um aparelho fotográfico é forçadamente levado por um sujeito sensível a produzir superfícies simbólicas que, de uma maneira ou de outra, já se encontram pré-inscritas em seu modo de operar. Composto de símbolos permutáveis, de caráter manipulável e interativo, o visível que transcende é tão dependente de suas especificidades quanto da visão daquele que com ele age. Situação esta que se assemelha a um jogo de domínios no qual o aparelho é dominado pelo sujeito tanto quanto este o domina. Por conseguinte, na busca e realização de um golpe certeiro, dois sujeitos permeados por um condicionamento entre homem e máquina, segundo Couchot (2003), afinam-se: um sujeito sensível (homem) e um despersonalizado (máquina).

De aspecto instrumental e inteligente, como software ou "objeto impalpável" (FLUSSER, 2011) o aparelho possibilita liberar o sujeito sensível de tutelas ligadas à criação da imagem (esta sendo resultado de uma tecnologia), deixando-o livre para desempenhar um papel importante na realização da fotografia: o ato fotográfico. À medida que é instalado pelo sujeito sensível, que manipula o aparelho e age em função de um referente, o ato fotográfico torna-se um processo interativo, que segundo Soulages (2010) pode ser classificado de "relação", e que por fim origina a imagem fotográfica. E esta, por sua vez, torna-se uma evidência aparente, um ponto de vista subjetivo, fundado durante o relacionamento efetivado.

É este caráter simbólico do aparelho, de "aspecto mole" que, segundo Flusser (2011), assegura as virtualidades de realizar fotografias e, portanto, constitui a ele valor. Assim, portátil e móvel, programado para produzir automaticamente fotografias, o aparato fotográfico passa a confirmar a ideia de que a imagem é a corporificação pura de uma pirâmide visual particular. Metáfora de janela, aberta ao mundo, conforme afirma Aumont (2001), esta pirâmide é um indicador de visão que, como uma moldura, designa um mundo subjetivo e que por meio da fotografia se faz notável. Neste sentido, sob a direção de um centro absoluto (o olhar do sujeito sensível), toda moldura ou enquadramento da imagem fotográfica estabelece uma relação entre o olho fictício (o sujeito despersonalizado) e as coisas ao seu redor.

Comparando o telefone móvel com um aparelho fotográfico automaticamente simples, de poucas e pré-estabelecidas configurações (abertura, velocidade e ISO), certifica-se de que, por meio deste dispositivo, o sujeito opta por exercer uma técnica de captura fotográfica muito limitada. Logo, suas operações são determinadas pelo número de categorias pré-inscritas no programa do dispositivo. Contudo, esta limitação pode ser subvertida por seu sistema inteligente que, ao contrário das câmeras convencionais, oferece uma gama incontável de aplicativos fotográficos eletrônicos (softwares) para que o sujeito personalizado amplie seu potencial criativo referente a estas novas aparências visíveis.

Agregado de um conjunto de linguagens, programas e códigos, todos potencializados por sua condição ubíqua e móvel, o telefone móvel permite que a modificação, distribuição e disseminação da matriz fotográfica se dê de maneira extensa a sua obtenção. Como consequência, a fotografia móvel proporciona uma visão de mundo imediata ao espectador - mesmo que distante - e passa a proporcionar uma sensação de contato que é capaz de substituir, muitas vezes, a presença física e real das partes implicadas em sua rede de transmissão. Mediante uma lógica de interação, imediata à captura ou na sucessão deste ato, surgem inúmeras potencialidades artísticas relacionadas à fotografia móvel e que permitem distingui-la das demais categorias fotográficas.

Por esta razão, ao explorar o essencial do processo fotográfico, que possui diferentes possibilidades criativas no próprio suporte de criação, ou seja, na capacidade do aparelho de ir além da interatividade convencional apresentada pelas demais câmeras, permite pensar a manipulação e distribuição da fotografia como ações extensas ao ato fotográfico e, por sua vez, expandindo-o de maneira direta e instantânea.

Em ação conjunta com o sujeito, o telefone móvel tal como um o aparelho fotográfico, que, segundo Flusser (2011), é o produto de uma técnica a qual advém de textos científicos aplicados e capazes de traduzirem o pensamento conceitual em fotografias, produz imagens e estas, por sua vez, tornam-se aparências reais de uma capacidade de abstração específica da imaginação do sujeito sensível, bem como produto indireto da ciência. Neste sentido, o sujeito realiza boa parte das operações de ver e representar de modo dependente do maquínico e pode ser chamado, com base em Couchot (2003), de sujeito aparelhado. Submisso às funções do aparelho, este sujeito é obrigado a, antes de mais nada, transcodificar suas intenções em "conceitos", que segundo Flusser (2011) são gestos técnicos e, assim, no momento decisivo e na continuidade dele, conceitos em imagens; no caso específico da fotografia móvel, muitas vezes circulando na rede, imagens em fluxos.

Aparelhado, este sujeito não se encontra em situação de controle na realização da foto, pois parte dos procedimentos de produção dependem da tecnologia ligada a sua 'máquina falante'. Manipulando técnicas como um conjunto de processos que transformam a percepção de mundo, o sujeito vivencia uma experiência singular. Experiência esta tecnestésica que, segundo Couchot (2003), associa uma tecnicidade figurativa e uma figura 
de subjetividade, e que, em outras palavras, funde atividades de duas figuras ou sujeitos distintos: o homem e a máquina. Figuras estas que se afrontam e se relacionam, deslocam-se e trocam de posição continuamente, assumindo assim um mesmo estado de sujeito (COUCHOT, 2003).

De gestos automatizados por tecnologias simbólicas, este sujeito aparelhado, em sua relação com a máquina - ou diálogo interativo - opera num modo indefinido. A sua singularização, em função da coletividade maquínica, tende a enfraquecer e despersonalizar. Para Couchot (2003), trata-se de um sujeito faceado e conduzido pelo automatismo do dispositivo técnico e que no íntimo de suas experiências tecnestésicas, passa a dispor de outros meios que the permitem novas possibilidades de se manifestar.

Indefinido e desprovido de identidade, operando sob a influência do maquínico, o sujeito aparelhado funciona de modo impessoal e anônimo. Contudo, isto não significa que ele se prive de suas qualidades subjetivas e se torne um objeto. Ao contrário, como escreve Machado (2001), mesmo que substituído por processos automatizados, seu olhar é potencializado, ampliado. E isto, por consequência, reforça seu papel estruturante e, assim, "a razão plena do ato da figuração".

Através de ações definidas programaticamente, este sujeito aparelhado coloca de lado (sem renunciar) o "inconsciente psíquico, imponderável e polissêmico", que, por sua vez, the permite atuar em uma "espécie inconsciente maquinal e multiforme", ou seja, sob forte influência do dispositivo (MACHADO, 2001). Como se operasse uma caixa preta, o funcionamento enigmático do aparelho pode até lhe fugir do conhecimento, porém isso não significa que não possa operá-lo.

Deste encontro, um sujeito despersonaliza e o outro assujeita. Como um diálogo de contrabalanços, no qual a visão é comandada pela automatização e esta é manipulada pelo sujeito personalizado, a fotografia emerge como o resultado puro de um jogo de vice-e-versa. Na busca de um conceito, a ação de fotografar compara-se a uma conversa intensa. Um diálogo no qual um sujeito (sensível) desencadeia um processo e narra uma história e o outro (insensível) programa automaticamente as situações narrativas que recebe (MACHADO, 2001).

Com a introdução do numérico, esta relação entre os sujeitos passa a ser classificada por Couchot (2003) como condicionamento conversacional ou interativo, pois uma imagem eletrônica surge do vínculo estabelecido e apresenta certo grau de interatividade latente em sua morfogênese; o que, por sua vez, permite que o diálogo entre os sujeitos se complexifique ainda mais por conta do tratamento das informações trocadas.

Levando em consideração a vasta capacidade computacional do telefone móvel atualmente, é difícil desvincular as intenções de criação deste raciocínio no qual o maquínico se impõe à produção de fotografia móvel, afirma-se e alimenta a criação. Numa espécie de "relação simbiótica" (PLAZA, 1998), regida por regras sintáticas inerentes ao maquínico, bem como pela volúpia subjetiva do gesto criador, diversos instantâneos voláteis e fotografias expandidas surgem como "registros sinérgicos" de uma "relação interdisciplinar", ou seja, entre "práticas e saberes, técnica e linguagem" (PLAZA, 1998). Relação esta também classificada por Couchot (2003) como "interatividade numérica", ou seja, dependente de uma codificação, estabelecida entre a linguagem lógica e a linguagem do corpo, onde a interface do aparelho móvel torna-se um elemento codificador de ações e percepções.

Embora apresente os mais variados tipos de aplicações e possibilidades computacionais, o telefone móvel impõe ao sujeito personalizado limites que são completamente estabelecidos por programas; ultrapassar tais limites, ou usá-los em favor de ações criativas e sensíveis, é um desafio para muitos artistas e fotógrafos interessados em uma prática de transformação e certificação da fotografia móvel no campo da arte tecnológica atual.

Baseado em menus, que permitem escolhas e diferentes opções previamente determinadas, o processo de produção fotográfica diz respeito a uma forma de interatividade complexa, dependente de sinais eletrônicos e que se desenvolve de "maneira aberta" (entre o homem e o computador, sem que o conteúdo seja determinado a priori, MANOVICH, 2001), pois, de acordo com as ações do sujeito, gera conteúdos em tempo real e disponíveis em diferentes espaços. Desta maneira, a captura da fotografia móvel é um processo dialógico resultante de um momento tecnológico no qual, segundo Manovich (2001), novas tecnologias comunicacionais permitem uma interferência mais intensa entre os diferentes sujeitos implicados na conversação ou relação homem-máquina.

É esta arborescência tecnológica que passa a favorecer o surgimento de novas aparências visuais, como a fotografia móvel, e enriquecer o panorama das ações interativas e participativas que se realizam e se consomem na efervescência de produções na rede. Assim, na busca de uma subjetividade apoiada neste tipo de sujeito despersonalizado que é o telefone móvel, muitas poéticas levam em conta não apenas a interação entre os diferentes sujeitos aqui discutidos mas, também, a dinâmica da imagem criada e a extensão desse diálogo conversacional a outros sujeitos definidos.

Resultante de um momento de equilíbrio expressivo extraído de um instante decisivo, a fotografia atualmente permite coincidir o fluxo pessoal do sujeito com o fluxo das coisas intrínsecas do dispositivo. A inclusão destes novos aparatos passa a favorecer a captura fotográfica no meio social atual, e não somente revela a imposição da fotografia a muitos desafios ligados à técnica fotográfica como também comprova que esses desafios não se encontram esgotados. 


\section{Referências}

Aumont, J. ( 1993). A imagem. São Paulo : Papirus.

Bauman, Z. (2001). Modernidade Líquida. Rio de Janeiro: Jorge Zahar Ed.

Couchot, E. (2003) A tecnologia na arte: da fotografia à realidade virtual. Tradução de Sandra Rey. Porto Alegre: Editora da UFRGS.

Flusser, V. (2011). Filosofia da Caixa Preta: ensaios para uma futura filosofia da fotografia. Apresentação de Norval Baitello junior. - São Paulo; Annablume.

Kossoy, B. (2001). Fotografia e história. 2o ed. rev. - São Paulo: Ateliê editorial,.

Machado, A. (2001). O sujeito no ciberespaço. In: INTERCOM XXIV Congresso Brasileiro da Comunicação - Campo Grande /MS.
Manovich, L. (2000). The language of new media. Cambridge: The MIT Press,.

Novas Mídias como tecnologia e idéias: dez definições. In LEÃO, L. 2005. O chip e o caleidoscópio: reflexões sobre as novas mídias. São Paulo: Ed. SENAC.

Plaza, J. (1998). Processos criativos com os meios eletrônicos: poéticas digitais. São Paulo: FAEP-UNICAMP Ed. Hucitec.

Santaella, L. Linguagens Líquidas na era da mobilidade. São Paulo: Ed. Paulus, 2007

Soulages, F. (2010). Estética da fotografia: perda e permanência. Tradução de Iraci D. Poleti e Regina Salgado Campos. São Paulo: Editora Senac São Paulo. 